\title{
Isolation and insight: practical pillars of revalidation?
}

\section{INTRODUCTION}

The imminent introduction of revalidation, 'the process by which doctors will, in future, demonstrate to the General Medical Council (GMC) on a regular basis that they remain up to date and fit to practise', obliges us to ask what guiding principles should be addressed as we implement revalidation? Seven years ago Good Medical Practice (GMP) for GPs stated, 'the unacceptable GP has little knowledge of developments in clinical practice; has limited insight into the current state of his or her knowledge or performance; selects educational opportunities which do not reflect his or her learning needs; does not audit care in his or her practice, or does not feed it back into practice,' and 'is hostile to external audit or advice. ${ }^{2,3}$

The five characteristics of the acceptable GP are the converse of the unacceptable one, but in our experience are not applicable to the complete breadth of a doctor's work. As we have assessed GPs whose performance has raised serious concerns ${ }^{4}$ we have found repeatedly that basic failures in diagnosis, poor management and haphazard follow-up are clear to assessors. It is clear that such doctors lack insight into their deficiencies and are often isolated from peers who may reveal and help correct them. Indeed GMC reports of GPs whose names have been erased from the medical register frequently cite a lack of insight as the root of their negligent performance. This leads us to propose that isolation and insight be two pillars upon which revalidation is practically based. In short, for a GP to be revalidated there would have to be convincing evidence that they were neither isolated nor lacking insight.

\section{ISOLATION}

GPs may be isolated by virtue of being single handed or a locum or by the dysfunctional working of their professional or group practice. III health is a significant factor in about $20 \%{ }^{5}$ to $27 \%{ }^{4}$ of cases of underperformance. Furthermore, doctors commonly face systematic barriers to accessing health care, and good management of their health should not be assumed. ${ }^{6}$

Isolation ought to be lessened by relationships within the primary healthcare team, especially fellow GPs who should share the daily interest, frustrations, and serendipity of the job. Outside the boundaries of individual practices 'collegiality' may also lessen isolation, for instance young and old principals groups. Surveys in the Mersey region in 1989 and 1998 showed $35 \%$ of principals attended a professional small group at any one time, 'a self-motivated commitment to professional development often unrecognised by formal systems'. ' We do not know how many GPs currently participate in professional small groups and the future may involve seeing federations of practices or practice-based commissioning consortia taking their place. ${ }^{8}$

Professional contact with one's peers should help maintain and develop knowledge through formal events and small group or practice-learning sessions. Although we consider that there is no substitute for reading professional journals, it is critical discussion with peers which particularly enables new learning to be understood and placed in context. A single-handed GP or locum could become isolated through the absence of networking and support, but a substantial review of their work did not show that they underperform clinically. ${ }^{9}$

Professional isolation is indefensible ${ }^{10}$ and although appraisal has potentially lessened the isolation of some, appraisal may still run the risk of gaming, collusion and 'playing the system'. ${ }^{11}$ Role models can powerfully shape behaviour and attitudes in students, which may persist throughout professional life, ${ }^{12}$ and contact with peers should reinforce good models. Mentoring can also positively influence doctors, 'improve healthcare standards and services"13 and reduce isolation. It has been reported that benefits reported by doctors includes an increased sense of collegiality. ${ }^{14}$

\section{INSIGHT}

Long-standing mediocre performance is often difficult to manage and remedy due to a lack of insight, ${ }^{15}$ which is perhaps the most crucial attribute of the 'acceptable GP'. The 1990s were a decade of professional selfaudit when the insight gained through examining one's own performance should have led to deficiencies being corrected. ${ }^{16}$ Insight can develop through both systematic clinical and Significant Event Audit. The Quality and Outcomes Framework (QOF) has succeeded because the rapid electronic feedback of data has given awareness of deficient performance that can be remedied.

Unfortunately, for a minority of doctors, arrogance leads them to being hostile to external audit or advice. ${ }^{2}$ Since in many healthcare activities serious harm is "but a few unguarded moments away ${ }^{17}$ clinicians, including GPs, remain the primary defence, not least for the insight they should bring to the possibility that wrong assumptions are harming, or could harm, a patient. One of the recognised early signs of the doctor in difficulty is 'insight failure: rejection of constructive criticism; defensiveness; counter-challenge'. ${ }^{15}$

It is also difficult to gain insight without feedback from patients and colleagues. Feedback from consultations and discussions with informed peers are often necessary to see the larger picture and turn anecdotes into information. Perhaps the greatest difficulty GPs face is in acknowledging both the limits to their competence, or whether they are being too cautious in over-referring patients to services that will manage them less well than themselves. Furthermore, we must practice the medicine of uncertainty, ambiguity and complexity, ${ }^{18}$ balancing conflicting priorities and working beyond even the best clinical guidelines, which NICE considers unlikely to be able to accommodate more than around $80 \%$ of patients for whom it has been developed. ${ }^{19}$

\section{CONCLUSION}

For revalidation to succeed it will be necessary for the profession to agree that judgements that a doctor is 'up-to-date and 
fit to practise' are fair and valid. These difficult judgements must involve more than counting courses attended and hours spent listening to lectures. We believe isolation and insight are readily understandable to our profession and able to be stated in operational terms and we offer them as two pillars upon which these judgements could be based.

\section{Stephen J Cox and John D Holden}

\section{REFERENCES}

1. GMC. Revalidation. http://www.gmcuk.org/about/reform/Revalidation.asp (accessed 1 Jun 2009).

2. RCGP. Good medical practice for general practitioners. Maintaining good medical practice. http://www.rcgp.org.uk/PDF/Corp_GMP06.pdf accessed 15 Jun 2009).

3. RCGP. Good medical practice for general practitioners. http://www.rcgp.org.uk/pdf/PDS_Good_Medical_Practic e_for_GPs_July_2008.pdf

4. Cox SJ, Holden JD. Presentation and outcome of clinical poor performance in one health district over a 5 -year period: 2002-2007. Br J Gen Pract 2009: 59; 344-348.

5. National Clinical Assessment Service. Analysis of the first four years' referral data. London: NCAS, 2006.

6. Kay M, Mitchell GK, Clavarino AM, Doust J. Doctors as patients: a systematic review of doctors' health access and the barriers they experience. Br J Gen Pract 2008; 58: 501-508.

7. Howard, JC. Small Groups in Mersey region 1989-1998. Educ for Gen Pract 2001; 12: 47-57.

8. Anonymous. Federations in action: the St Helens experience. RCGP News 2009; Jan: 8 .

9. Hippisley-Cox J, Pringle M, Coupland C, et al. Do single handed practices offer poorer care? Cross sectional survey of processes and outcomes. BMJ 2001; 323: 320-323.

10. Pringle M. The Shipman Inquiry: implications for the public's trust in doctors. Br J Gen Pract 2000; 50: 355-356.

11. McKinstry B, Peacock H, Shaw J. GP experiences of partner and external peer appraisal: a qualitative study. $\mathrm{Br}$ J Gen Pract 2005; 55: 539-543.

12. Lublin JR. Role modelling: a case study in genera practice. Med Educ 1992; 26: 116-122.

13. GMC. Licensing and revalidation. http://www.gmcuk.org/register/licensing/index.aspuk.org/register/licensin g/index.asp (accessed 1 Jun 2009).

14. BMA. Board of Medical Education. Exploring Mentoring. http://www.academicmedicine.ac.uk/uploads/BMA\%20 mentoring.pdf (accessed 12 Jun 2009).

15. Cox J, King J, Hutchinson A, McAvoy P. Understanding Doctor's performance. Oxford: Radcliffe Publishing, 2006.

16. Holden J. Systematic review of published multi-practice audits from British general practice. I Eval Clin Pract 2004; 10: 247-272.

17. Reason J. Beyond the organisational accident: the need for "error wisdom" on the frontline. Qual Saf Health Care 2004; 13 (Suppl 2): ii28-ii33.

18. Medical Schools Council. The role of the doctor: past, present and future. A celebration of 150 years of the Medical Act. Consensus statement. http://www.chms.ac.uk/RoleoftheDoctor2008.htm (accessed 1 Jun 2009).

19. NICE. Response to the report of the Bristol Royal Infirmary Inquiry.

http://www.nice.org.uk/niceMedia/pdf/bristolreportrespo nsefinal.pdf (accessed 1 Jun 2009).

DOI: 10.3399/bigp09X453675

\section{Reflections in a cracked mirror}

How I hate the modern obsession with reflection.

After every talk and lecture, at almost every trainers and appraisers meeting for the last few years and in everything associated with the medical learning industry, I am encouraged to reflect. To reflect on what I have learned and to shine that secondhand light on how my new knowledge will change the way I practise.

There are now Structured Reflective Templates as part of our annual appraisals. A contradiction in terms if ever there was one.

I have been a doctor for a third of a century. Seeing, thinking, absorbing, accommodating, and altering the way I work. Daily, hourly, constantly. I see what makes sense, what works better and I automatically adapt. Without thinking.

After all, isn't that what professionals do?

Usually this is a natural and subliminal process without recourse to protected time, a formal thought pattern or that selfconscious, unnecessary, and artificial selfanalysis of reflection. We don't need to be told to do the obvious.

It works like this: someone with more experience tells you what works for them and you try it out yourself next time an appropriate situation arises. Thus, it has always been.

Or you do something that doesn't work and you don't do it that way again. In life as in medicine.

But for the last 5 to 10 years we have been encouraged to reflect on new information and how it will change us. This is like a photographer delaying the taking of a picture long enough to analyse why he is taking that particular picture. Or wondering how that picture will influence the viewer once he has taken it, rather than being spontaneous, instinctive, natural.

But it is worse than that. It isn't just that the whole process of being asked to reflect is artificial pointless and patronising; reflection isn't even a correct use of the word.
I mean, if they can get the concept so wrong, how can we trust anything they ask us to do?

You see the problem is this: reflecting is what mirrors and burnished surfaces do. They bounce incoming energy, that is, light, off their surfaces. The light doesn't penetrate their smooth skins and in the process the light is turned upside down. They are blissfully unaffected by it. Lateral inversion, left to right, back to front.

So reflection is a process whereby the reflector is uninfluenced by the reflecting, the incoming energy is turned upside down and reality is distorted.

So next time you are asked to reflect on a piece of information or an experience just bear in mind the fact that doing so won't change you. The moment you start you will instantly get it all back to front and, anyway, isn't it faintly narcissistic to keep reflecting like that?

Surely if we are talking about the physics of processing energy, what we should be doing is diffracting or refracting.

You see, these are processes whereby a prism or other penetrable transparent surface separates and defines the important constituents of incoming light, changes it, interprets it in a new way and helps clarify its secrets.

It is an even more appropriate term when you find out that the refractive index is related to the denseness of the medium.

Also the process is often startlingly pretty and always a pleasant surprise.

Now diffusion: that is something completely different.

\section{Chris Heath}

DOI: 10.3399/bjgp09X453684 